\title{
The man who claimed to be a paedophile
}

\author{
Simon A Hill Senior House Officer in Acute and Rehabilitation Psychiatry
}

\begin{abstract}
A psychiatrist recounts a case of a man presenting with severe depression who claimed to have abused children and his pet dog.

Clinical management of the case hinged on whether this claim was true, a lie or delusional. The uncertainty over this raised complex ethical dilemmas regarding confidentiality and protection of the public (and animals).

(Fournal of Medical Ethics 2000;26:137-138)
\end{abstract}

Keywords: Paedophilia; confidentiality; duty to public; psychotic depression

$\mathrm{Mr} \mathrm{X}$ is a 67 -year-old retired foundry worker who lives an isolated and lonely existence in an inner city flat.

He was rejected at birth by his prostitute mother and was brought up by nuns in a Roman Catholic orphanage. During this time he was sexually abused by older boys. Apart from four years in the army catering corps he has always lived alone.

He has never had a confiding relationship with anyone and is confused about his sexual orientation. Throughout his life $\mathrm{Mr} \mathrm{X}$ has sought company in male institutions such as the army, the Scout association and football clubs. Being a scout leader and a coach of youth football teams used to take up some of his spare time. Now he has retired from these pursuits he spends his time in his flat with his pet dog. He does however attend a charitable-run day centre twice weekly as a "helper"/member. His only recreation is watching local football on Saturdays. He was an alcoholic for many years but has not had a drink for 15 years.

Mr X was admitted to an acute psychiatric hospital three times between 1979 and 1981 with severe depressive episodes complicated by alcohol abuse. These depressive episodes had a psychotic component congruent with the depression. For example when unwell he tended to think people planned to harm him, and that they were justified in doing so. $\mathrm{He}$ also said things like "I'm the Devil" and "I'm evil and worthless". This is typical of a psychotic depression.

Mr X was admitted to an acute psychiatric hospital in September 1998 because he had been saying odd things to the warden of his flats, about abusing children and his dog. On admission he claimed to have abused six boy scouts while he was a scout master about 20 years ago. He said he fondled and put his finger "up their backsides". However, he maintained that this was all while he was drinking heavily. $\mathrm{Mr} \mathrm{X}$ also stated that he had fondled and masturbated his pet dog three months previously and let it lick Mr X's penis. Paranoid thoughts such as "the lynch mob are coming to get me and will burn down the city" were prominent. He said that he had the urge to go after children and found schoolboy football sexually arousing. Mr X said : "I always want children". Guilt was his main emotion and he said "I've sold my soul to the Devil".

Our initial diagnosis was of psychotic depression with mood-congruent delusions of guilt. He agreed to stay on the ward, where he was observed intermittently but not continuously by nursing staff. Unfortunately, he went missing the day after admission. What should we tell the police, regarding the possible risk to local children? At this stage, we had no clear evidence on which to assess whether he was a child abuser or not. It was decided initially to inform the police that our patient had absconded, was considered to be a risk to himself, and should be returned to the ward urgently. It was decided not (at least initially) to discuss his statements about the historical child abuse. In fact, he returned to the ward before it was felt necessary to inform the police. In total, he was an informal patient on the ward for two days before it was decided to detain him under Section 2 of the Mental Health Act (1983) to keep him in the hospital. Arguably, he should have been detained to protect the public and himself, from the time of admission.

Over the next few days the paranoid ideas left him and he became his normal withdrawn, lonely 
self. He said he had no sexual desire towards children at all. However, he still admitted to having abused children 20 years previously and to abusing his dog three months ago: "the worst thing I have ever done in my life". We still did not know whether he was a serial paedophile or whether these were the distorted and false memories of a man who without doubt loses touch with reality when he is depressed.

We did not know whether the tales of paedophilia and animal abuse were true. Inquiries showed that he was not known to the police or social services and that no complaint had ever been made about him. He was able to name the scout troop where he had been a leader and said that he could remember the names of some of the boys he had abused, although interestingly he consistently failed to disclose any specific names at any point. We decided not to contact the scout troop in question to make further enquiries. Theoretically it would have been possible to trace the men who had been in the troop as boy scouts 20 years previously. After finding them we could have seen if any of them wished to disclose and/or offered them counselling. However, not only would this have been impractical but we felt that this course of action was unlikely to improve these men's lives and could be disturbing for them. Most would be married with families and discussion of the sordid events of 20 years ago might not be welcome. As Mr X refused to tell us the names of any of the people he had abused it would have been very difficult to establish from first-hand accounts whether his claims were true. Arguably, we should have tried.

We decided that our duty to protect the public from possible risk was sufficient that we had to involve other agencies, and interestingly we were able to do this with the patient's agreement, rather than requiring any breach of confidentiality. A special "at risk" meeting was called, to which various agencies were invited, including $\mathrm{Mr}$ X's general practitioner and the police. The meeting was chaired and convened by the county "Adults at Risk" social services manager. $\mathrm{Mr} \mathrm{X}$ was informed that such a meeting would take place, but was not invited to attend. The meeting concluded that there might be a potential risk to children when he was mentally unwell, but that with ongoing psychiatric treatment, together with careful psychiatric follow up in clinic and in the community by a nurse, this risk could be minimised. We also organised for him to be assessed for ongoing counselling by a senior psychologist in the mental health unit. The police did not want to take any action or to investigate further, on the basis that the only evidence was $\mathrm{Mr}$ $\mathrm{X}$ 's word and as such was hearsay.

It was also decided at this multiagency meeting that he should be allowed his dog back from kennels. This was obviously controversial but it was felt that without his dog he was more likely to become depressed and be a risk to children.

Months on, Mr X's depression seems a little better. He still lives his lonely life and he still claims to have been a child abuser in the past. It is unlikely that we will ever know the truth. We took his stories seriously despite his mental illness. In our view it was the only way to protect (and to be seen to protect) the public.

\section{Acknowledgements}

The author would like to thank Julie Bundy for her help in preparing this manuscript.

Dr Simon A Hill, $M A, B M, B c h$, is a Senior House Officer in Acute and Rehabilitation Psychiatry. 